\title{
AVALIAÇÃO DO USO DE ULTRASSOM NA PRODUÇÃO DE ÁCIDOS GRAXOS VIA REAÇÃO DE SAPONIFICAÇÃO SEGUIDA DE HIDRÓLISE ÁCIDA
}

\author{
L. P. LIMA ${ }^{1}$, F. A. N. FERNANDES ${ }^{1}$ \\ ${ }^{1}$ Universidade Federal do Ceará, Departamento de Engenharia Química \\ E-mail para contato: larispinto@yahoo.com.br; fabiano@ufc.br
}

\begin{abstract}
RESUMO - Ácidos graxos foram produzidos a partir de óleo residual por reação de saponificação seguida de hidrólise ácida assistida. As reações de saponificação foram realizadas em um reator químico de vidro sobre influência de um ultrassom tipo sonda e um reator químico de vidro submerso em banho de ultrassom. Um planejamento

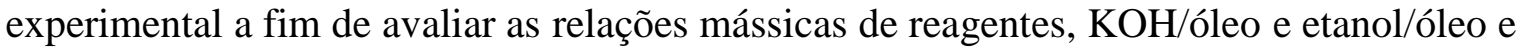
densidade de potência. Conversões de $100 \%$ foram obtidas para as reações de saponificações submetidas a sonda ultrassônica ao reagir 0,3 KOH/óleo e 2,4 EtOH/óleo a $0,8 \mathrm{~W} / \mathrm{mL}$ e 1,6 W/mL e 0,37 KOH/óleo e 1,6 EtOH/óleo a 1,2 W/mL e 94,3\% quando utilizou-se 0,3 KOH/óleo, 2,4 EtOH/óleo a 0,018 W/mL para as reações de saponificações realizadas no banho de ultrassom. Dentre as variáveis do processo a que mais afetou a reação de saponificação, de acordo com o estudo estatístico, foi a relação mássica de $\mathrm{KOH} /$ óleo. O resultado do estudo comparativo entre as duas metodologias estudadas apresentou uma média de conversão $20 \%$ maior paras as reações de saponificação realizadas no ultrassom tipo sonda. Ao comparar o consumo energético dos dois processos observou-se que o banho de ultrassom tem um consumo cerca de 10,7 vezes menor do que o ultrassom tipo sonda. $\mathrm{O}$ banho de ultrassom destacou-se no processo de obtenção dos ácidos graxos, pois apresenta o favorecimento de altas conversões, baixo consumo energético e menor tempo total do procedimento operacional.
\end{abstract}

\section{INTRODUÇÃO}

Ácidos graxos são ácidos carboxílicos de cadeia longa que apresentam especial importância nas indústrias alimentícia e farmacêutica (Rodríguez et al., 2010), sobretudo pela grande utilização em Nutrição Humana. Os ácidos graxos podem, ainda, ser utilizados sob a forma de ésteres ou sais de ésteres na preparação de uma variedade de produtos, tais como aromas, sabões, surfactantes, medicamentos, perfumes, cosméticos, produtos de componentes alimentares, biopesticidas e biocombustíveis (Ullmann’s, 1999).

Os ácidos graxos podem ser obtidos a partir da hidrólise de triglicerídeos, que são comumente chamados de óleos e gorduras. Diferentes processos de hidrólise são propostos para a produção desses 
ácidos, tais como hidrólise, hidrólise enzimática e hidrólise básica seguida de hidrólise ácida (Martinelli, 2008). Dentre esses os processos de obtenção de ácidos graxos, a hidrólise associada a altas temperaturas e ao uso de catalisadores heterogêneos é o processo mais utilizado industrialmente, mas o desenvolvimento de processos com menores gastos energéticos, que proporcionem menor tempo de reação e que utilizem matérias primas de baixo valor comercial é primordial para a redução de custos das reações de hidrólise de triglicerídeos visando à produção de ácidos graxos, tornando-a economicamente viável.

O uso de óleos residuais vem ganhando espaço, cada vez maior, não só pela questão ambiental, mas por virem se apresentando como boa alternativa, enquanto matéria prima, em diversos processos químicos industriais (Veloso et al., 2012).

O processo convencional e aquecimento e agitação vigorosa utilizada nas reações podem ser substituídos por tecnologias como o ultrassom que possui várias vantagens como: redução do tempo de reação, aumento do rendimento e seletividade e favorecimento de reações que normalmente não ocorrem em condições normais.

O ultrassom é um fenômeno físico que influencia no processo de criar, aumentar e implodir cavidades de vapor e gases, denominado cavitação, em um líquido (Martines et al., 2000). A incidência do ultrassom pode resultar na aceleração de alguns processos químicos, bem como a geração de produtos (Mason et al., 2002).

Desta forma, este trabalho tem como objetivo estudar a influência e diferença do banho de ultrassom e do ultrassom tipo sonda no processo de produção de ácidos graxos via reação de saponificação seguida de hidrólise ácida, bem como avaliar suas condições reacionais fazendo o estudo estatístico das variáveis independentes do processo, concentração de hidróxido de potássio, concentração de etanol e potência do ultrassom.

\section{MATERIAIS E MÉTODOS}

\subsection{Materiais}

O óleo residual utilizado para realização desse estudo foi o óleo pós-fritura, obtido, em um único lote, pela Panificadora Costa Mendes. A Panificadora Costa Mendes utiliza a Gordura de Palma $370 \mathrm{~F}$ da AGROPALMA para realizar a fritura dos seus produtos. A fim de se obter a completa remoção de materiais em suspensão e umidade presentes no óleo, foi realizado um pré-tratamento, no qual o óleo foi filtrado, desumidificado e aquecido até $110^{\circ} \mathrm{C}$ por 10 minutos.

Os demais reagentes foram adquiridos em grau analítico (P.A.) e usados sem tratamento prévio: ácido sulfúrico, álcool etílico, hexano e hidróxido de potássio (Synth - Diadema, SP, Brasil). 


\section{9 a 22 de outubro de 2014 \\ Florianópolis/SC}

\subsection{Produção dos ácidos graxos}

O procedimento de produção de ácidos graxos a partir dos óleos vegetais e/ou gorduras animais foi dividido em duas etapas: reação de saponificação seguida de uma reação de hidrólise ácida e foram adaptados de Mano (1987).

Reações de saponificação: Para o desenvolvimento deste trabalho foi avaliado a conversão do óleo residual em ácidos graxos quando as reações foram irradiadas em banho de ultrassom (UNIQUE USC 2850A) e com um ultrassom tipo sonda (UNIQUE DESRUPTOR DES500).

As reações de saponificação foram realizadas em um reator químico de vidro de $250 \mathrm{~mL}$, sobre influência de ultrassom transferido por uma sonda, operando a uma frequência de $19 \mathrm{kHz}$ e um reator químico de vidro de $250 \mathrm{~mL}$ submerso em banho de ultrassom operando a uma frequência de $25 \mathrm{kHz}$.

O planejamento experimental apresentado na Tabela 1 foi gerado a partir das faixas de relações mássicas de reagentes, $\mathrm{KOH} /$ óleo $(0,1-0,3 \mathrm{~m} / \mathrm{m})$, etanol/óleo $(0,8-2,4 \mathrm{~m} / \mathrm{m})$ e densidade de potência $(0,009-0,018 \mathrm{~W} / \mathrm{mL}$ para o banho de ultrassom e $0,8-1,6 \mathrm{~W} / \mathrm{mL}$ para o ultrassom tipo sonda).

$\mathrm{Na}$ realização dos experimentos, a solução de $\mathrm{KOH}$ em etanol foi adicionada ao óleo contido no reator, a potência dos ultrassons foram ajustadas de acordo com o planejamento experimental apresentado na Tabela 1 e o tempo reacional foi de 45 minutos para todas as reações de saponificação.

Reações de hidrólise: O produto da etapa de saponificação foi dissolvido com água destilada e, em seguida, foi adicionado a solução de ácido sulfúrico 5,5 mol/L. A mistura obtida foi transferida para um funil de decantação e, depois, a camada aquosa foi separada da massa de ácido sobrenadante. A massa de ácido graxo obtida foi lavada com água destilada e posteriormente foi aquecida até $110^{\circ} \mathrm{C}$ por 10 minutos para ser desumidificada.

Análise dos produtos: A metodologia para determinação do índice de acidez utilizada neste trabalho foi a metodologia sugerida pela American Oil Chemists Society (A.O.C.S.), método oficial Cd 3d-63 com adaptações, de acordo com o sugerido por Moreto et al., (1998).

\section{RESULTADOS E DISCUSSÕES}

A Tabela 1 apresenta os resultados obtidos para o planejamento experimental $2^{3}$ realizado a fim de avaliar a conversão do óleo residual em ácidos graxos quando as reações de saponificação são realizadas sobre irradiação ultrassônica.

Os melhores resultados obtidos para as reações de saponificações realizadas no banho de ultrassom foram 94,3\% quando utilizou-se 0,3 KOH/óleo, 2,4 EtOH/óleo a 18 W/L e 92,3\% quando utilizou-se 0,3 KOH/óleo, 2,4 EtOH/óleo a $9 \mathrm{~W} / \mathrm{L}$. Enquanto para as reações de saponificações submetidas a sonda ultrassônica conversões de $100 \%$ foram obtidas quando reagiu-se $0,3 \mathrm{KOH} / \mathrm{óleo} \mathrm{e}$ 
2,4 EtOH/óleo a 0,8 W/mL e $1600 \mathrm{~W} / \mathrm{L}$ e quando reagiu-se 0,37 KOH/óleo e 1,6 EtOH/óleo a 1200 $\mathrm{W} / \mathrm{L}$.

Tabela 1 - Resultados do planejamento experimental $2^{3}$ para o estudo da conversão do óleo residual em ácidos graxos para as reações de saponificação conduzidas sobre radiação ultrassônica

\begin{tabular}{|c|c|c|c|c|c|c|}
\hline & \multirow{2}{*}{ Experimento } & \multirow{2}{*}{$\begin{array}{c}\text { KOH/óleo } \\
(\mathrm{m} / \mathrm{m})\end{array}$} & \multirow{2}{*}{$\begin{array}{c}\text { EtOH/óleo } \\
(\mathrm{m} / \mathrm{m})\end{array}$} & $\begin{array}{c}\text { Densidade de potência } \\
\text { do ultrassom (W/mL) }\end{array}$ & \multicolumn{2}{|c|}{ Conversão (\%) } \\
\cline { 4 - 7 } & & & Banho & Tipo sonda & Banho & Tipo sonda \\
\hline 1 & 0,1 & 0,8 & 0,009 & 0,8 & 34,1 & 35,8 \\
\hline 2 & 0,1 & 0,8 & 0,018 & 1,6 & 36,4 & 39,3 \\
\hline 3 & 0,1 & 2,4 & 0,009 & 0,8 & 35,4 & 40,1 \\
\hline 4 & 0,1 & 2,4 & 0,018 & 1,6 & 31,2 & 41,1 \\
\hline 5 & 0,3 & 0,8 & 0,009 & 0,8 & 66,8 & 82,3 \\
\hline 6 & 0,3 & 0,8 & 0,018 & 1,6 & 75,3 & 79,4 \\
\hline 7 & 0,3 & 2,4 & 0,009 & 0,8 & 92,3 & 100 \\
\hline 8 & 0,3 & 2,4 & 0,018 & 1,6 & 94,3 & 100 \\
\hline 9 & 0,03 & 1,6 & 0,014 & 1,2 & 9,10 & 9,9 \\
\hline 10 & 0,37 & 1,6 & 0,014 & 1,2 & 85,3 & 100 \\
\hline 11 & 0,2 & 0,25 & 0,014 & 1,2 & 52,0 & 65,8 \\
\hline 12 & 0,2 & 2,94 & 0,014 & 1,2 & 75,6 & 89,6 \\
\hline 13 & 0,2 & 1,6 & 0,005 & 0,4 & 68,7 & 82,9 \\
\hline 14 & 0,2 & 1,6 & 0,023 & 2,0 & 75,7 & 85,7 \\
\hline $15(\mathrm{c})$ & 0,2 & 1,6 & 0,014 & 1,2 & 65,7 & 79,5 \\
\hline $16(\mathrm{c})$ & 0,2 & 1,6 & 0,014 & 1,2 & 67,2 & 79,6 \\
\hline
\end{tabular}

A Tabela 2 apresenta os estudos estatísticos da conversão do óleo residual em ácidos graxos quando realizadas no banho de ultrassom e com ultrassom tipo sonda. Esses valores se referem à influência que essas variáveis exercem sobre a resposta (conversão reacional) a um nível de $90 \%$ de significância. 


\section{9 a 22 de outubro de 2014 \\ Florianópolis/SC}

Tabela 2 - Análise da perturbação das variáveis de resposta causadas pelos fatores de conversão do óleo residual em ácidos graxos realizadas em banho de ultrassom

\begin{tabular}{|l|l|l|l|l|l|l|}
\hline \multirow{2}{*}{ Fator } & \multicolumn{3}{|c|}{ Banho de ultrassom } & \multicolumn{3}{c|}{ Ultrassom tipo sonda } \\
\cline { 2 - 7 } & \multicolumn{1}{|c|}{ Efeito } & Erro padrão & \multicolumn{1}{|c|}{$P$} & \multicolumn{1}{|c|}{ Efeito } & Erro padrão & $P$ \\
\hline Média & $\mathbf{6 6 , 2 7 5 2}$ & $\mathbf{1 , 8 1 8 1 1 5}$ & $\mathbf{0 , 0 0 0 0 0 0}$ & $\mathbf{8 0 , 1 6 0 9}$ & $\mathbf{3 , 9 0 5 4 4 3}$ & $\mathbf{0 , 0 0 0 0 0 1}$ \\
\hline KOH (L) & $\mathbf{4 6 , 6 5 3 1}$ & $\mathbf{1 , 3 8 8 4 4 5}$ & $\mathbf{0 , 0 0 0 0 0 0}$ & $\mathbf{5 1 , 7 8 5 9}$ & $\mathbf{2 , 9 9 5 8 9 6}$ & $\mathbf{0 , 0 0 0 0 0 2}$ \\
\hline KOH (Q) & $\mathbf{- 1 4 , 1 0 3 3}$ & $\mathbf{1 , 7 1 2 3 1 5}$ & $\mathbf{0 , 0 0 0 1 7 3}$ & $\mathbf{- 2 1 , 0 1 9 4}$ & $\mathbf{3 , 6 4 5 0 9 5}$ & $\mathbf{0 , 0 0 1 1 8 7}$ \\
\hline EtOH (L) & $\mathbf{1 1 , 6 9 9 2}$ & $\mathbf{1 , 3 9 4 9 1 9}$ & $\mathbf{0 , 0 0 0 1 5 6}$ & $\mathbf{1 2 , 1 0 0 4}$ & $\mathbf{2 , 9 9 5 8 9 6}$ & $\mathbf{0 , 0 0 6 8 1 1}$ \\
\hline EtOH (Q) & $-2,6790$ & 1,746729 & 0,175987 & $-4,6145$ & 3,645095 & 0,252459 \\
\hline POT (L) & $\mathbf{2 , 8 6 2 5}$ & $\mathbf{1 , 2 8 8 5 2 7}$ & $\mathbf{0 , 0 6 8 0 5 5}$ & 0,9811 & 2,982479 & 0,753361 \\
\hline POT (Q) & $\mathbf{2 , 4 9 1 3}$ & $\mathbf{1 , 2 6 5 3 4 2}$ & $\mathbf{0 , 0 9 6 5 0 0}$ & 0,1112 & 3,577448 & 0,976215 \\
\hline KOH x EtOH & $\mathbf{1 2 , 1 7 5 0}$ & $\mathbf{1 , 8 2 2 2 5 2}$ & $\mathbf{0 , 0 0 0 5 4 5}$ & 7,6000 & 3,914327 & 0,100221 \\
\hline KOH x POT & 3,0250 & 1,822252 & 0,147976 & $-1,7500$ & 3,914327 & 0,670506 \\
\hline EtOH x POT & $-3,1750$ & 1,822252 & 0,132081 & 0,2000 & 3,914327 & 0,960909 \\
\hline
\end{tabular}

Os valores em negrito representam os efeitos significativos a 90\%. KOH - relação mássica KOH/óleo; EtOH relação mássica EtOH/óleo; POT - densidade de potência.

Através da análise do valor de $p$ pode-se observar que variável relação mássica de $\mathrm{KOH} /$ óleo (L) é a variável que mais influencia na reação de saponificação para a obtenção dos ácidos graxos quando conduzidas em banho ultrassônico, seguida das variáveis EtOH/óleo (L), KOH/óleo (Q), interação $\mathrm{KOH} \times \mathrm{EtOH}$, Potência $(\mathrm{L})$ e $(\mathrm{Q})$. A análise do valor de $p$ também mostrou que a variável relação mássica $\mathrm{KOH} / o ́ l e o(\mathrm{~L})$ é a variável estatisticamente mais significante na produção dos ácidos graxos quando as reações de saponificações são submetidas ao ultrassom tipo sonda, seguida do seu efeito quadrático e do efeito linear da relação mássica EtOH/óleo, o que já era previsto devido os resultados obtidos para o banho de ultrassom.

A variável ETOH/óleo (L) possuiu o segundo maior efeito significativo. Por ser um efeito positivo, retrata que a conversão será maior com o aumento da quantidade de etanol. O etanol é solvente da mistura reacional, como explicado anteriormente, e para as reações químicas realizadas com ultrassom esse aumento da quantidade do solvente pode beneficiar a reação no aspecto de diminuir a viscosidade do meio reacional, facilitando a formação e colapso das bolhas de cavitação (Suslick, 1989; Mason et al., 2002).

Para as reações de saponificação realizadas no banho de ultrassom, a variável densidade de potência, efeito linear e quadrático, foram estatisticamente significativas. Os valores baixos e positivos desses efeitos mostram que o aumento da potência do ultrassom resulta em conversões do óleo residual em ácidos graxos um pouco maiores, o que é previsível, pois quanto maior a energia fornecida ao sistema maior taxa de reação (Brown et al.; 2009). Entretanto, a variável potência do ultrassom não apresentou significância, no intervalo de $90 \%$, na conversão do óleo residual em ácidos graxos para as reações de saponificação realizadas com a sonda ultrassônica. Supõe-se que a baixa potência o ultrassom já fornece a energia necessária para que a reação ocorra.

Ainda analisando a Tabela 2, observa-se que as conversões dos experimentos realizados com o 
ultrassom tipo sonda sempre foram superiores as conversões dos experimentos realizados com o banho de ultrassom, para facilitar a visualização desses dados a Figura 1 foi criada.

Essa "vantagem" apresentada pelo ultrassom tipo sonda pode ser explicada pelo grande quantidade de energia que é fornecida ao sistema, pois ao se compara as densidades de potência utilizadas nas reações, observa-se que as densidades de potência do ultrassom tipo sonda é em cerca 90 vezes maior do que a densidade de potência do banho de ultrassom.

Além da questão da perda de energia, outro aspecto analisado para os dois tipos de arranjo de ultrassom é o tipo de agitação que cada um proporciona no meio reacional. Através dos experimentos realizados foi possível observar que a agitação da mistura reacional no banho de ultrassom começa na interface líquido-líquido e se desloca para as extremidades, enquanto o ultrassom tipo sonda gera uma agitação mais vigorosa.

A diferença entre as conversões de cada experimento realizado no ultrassom tipo sonda e no banho de ultrassom está apresentada na Figura 2.

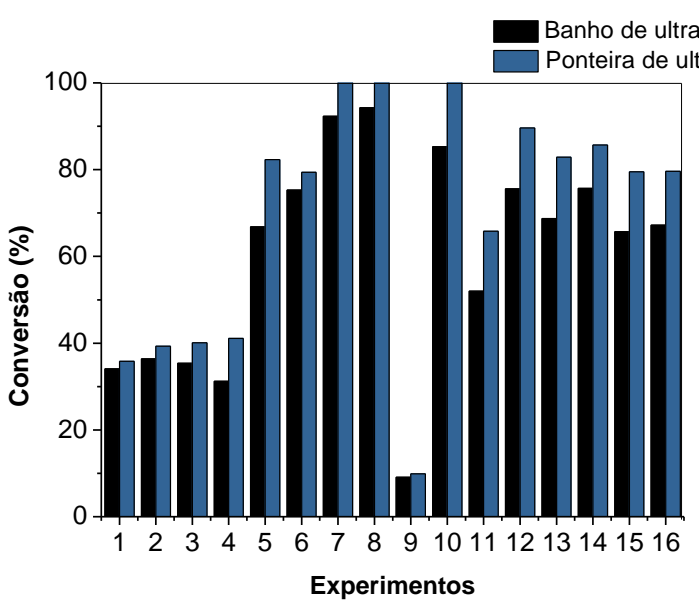

Figura 1 - Estudo comparativo entre as conversões do óleo residual em ácidos graxos para cada experimento realizado com banho de ultrassom e com o ultrassom tipo sonda.

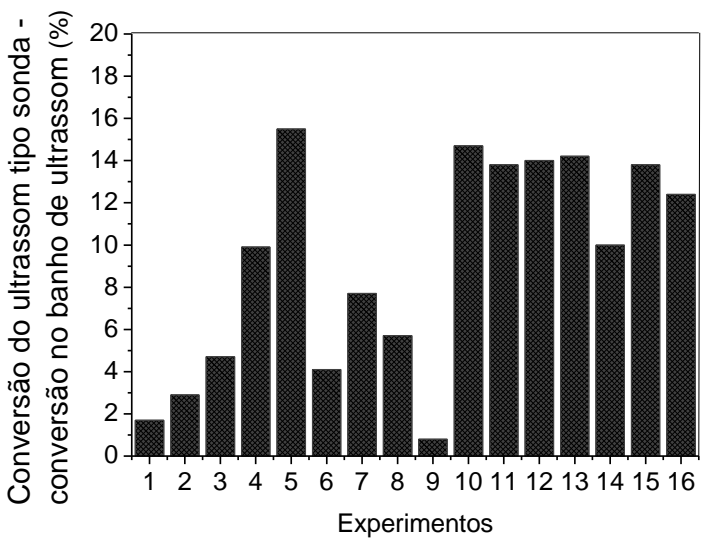

Figura 2 - Diferença entre as conversões de cada experimento realizado no ultrassom tipo sonda e no banho de ultrassom.

Para uma melhor visualização da influência do ultrassom nas reações de saponificação foram obtidas as curvas cinéticas da conversão do óleo residual em ácidos graxos. Para isso novos experimentos foram realizados, agora fixando as condições do ponto central do planejamento experimental da Tabela $2\left(0,2 \mathrm{KOH} /\right.$ óleo, 1,6 EtOH/óleo em $0,014 \mathrm{~W} / \mathrm{mL}$ e 1,2 W/mL $\left.{ }^{\circ} \mathrm{C}\right)$ e variando o tempo de reação nos seguintes intervalos de 1 a 60 minutos. Os resultados desses experimentos estão apresentados na Figura 3. 


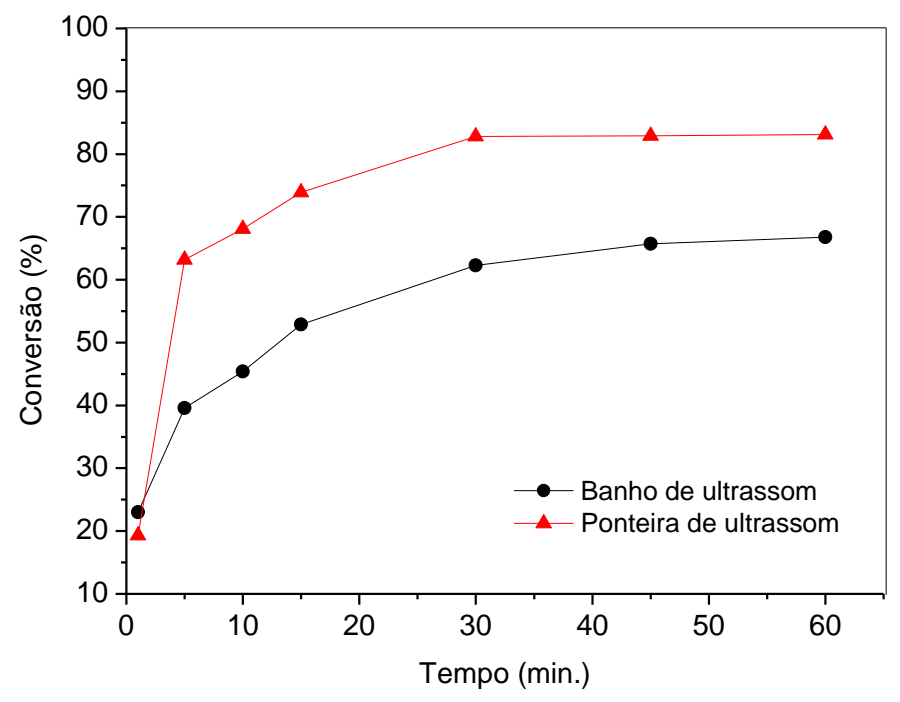

Figura 3 - Estudo comparativo da conversão do óleo residual em ácidos graxos entre as reações saponificação conduzidas no banho de ultrassom e com o ultrassom tipo sonda.

Na Figura 3 está visível que durante toda a reação houve uma diferença entre as reações sobre influência do ultrassom. Ao analisar a curva cinética da reação realizada com a sonda ultrassônica observa-se que ela manteve uma média de conversão de $20 \%$ acima quando comparada com a curva cinética da reação realizada com a sonda ultrassônica a partir dos 10 primeiros minutos. A diferença entre as duas curvas cinéticas chegou a ser de até 23,6\% nos primeiros 5 minutos de reação.

Consumo energético: A Tabela 3 apresenta os valores de energia elétrica consumida nas reações de saponificação para cada mol de produto formado.

Tabela 3 - Consumo de energia para cada técnica utilizada nas reações de saponificação

\begin{tabular}{|c|c|}
\hline Técnica & $\mathrm{kWh} / \mathrm{mol}$ \\
\hline Banho de ultrassom & 0,48 \\
\hline Ultrassom tipo sonda & 5,13 \\
\hline
\end{tabular}

Ao comparar o consumo energético do banho de ultrassom e ultrassom tipo sonda durante as reações de saponificação, observa-se que o ultrassom tipo sonda tem um consumo cerca de 10,7 vezes maior do que banho de ultrassom, tornando-se esse ultimo a técnica mais viável em termos de consumo de energia. $\mathrm{O}$ alto consumo de energia no ultrassom tipo sonda também está relacionado com a alta potência do banho termostatizado utilizado para resfriar o sistema e manter a temperatura reacional em $30^{\circ} \mathrm{C}\left( \pm 2{ }^{\circ} \mathrm{C}\right)$. 


\section{9 a 22 de outubro de 2014 \\ Florianópolis/SC}

\section{CONCLUSÕES}

Dentre os dois tipos de ultrassom estudados para a produção de ácidos graxos pode-se destacar o uso do banho de ultrassom como a metodologia mais indicada na etapa da reação de saponificação no processo de obtenção dos ácidos graxos, pois apresenta o favorecimento de altas conversões, baixo consumo energético e menor tempo total do procedimento operacional, além de não ser necessário um sistema de resfriamento no sistema. Esse baixo tempo total do procedimento operacional favorece na produção dos ácidos graxos para as reações de saponificação realizadas em série. O ultrassom de tipo sonda apresentou o favorecimento de boas conversões, porém esse apresentou um alto consumo energético, grande tempo total de procedimento operacional e necessidade de sistema de resfriamento, o que, para reações de saponificação em série, apresenta baixos rendimentos na produção.

\section{REFERÊNCIAS}

BROWN, L. S.; HOLME, T. A. Química geral aplicada à engenharia. São Paulo, Editora Cengage Learning, 2009.

MANO, E.B.; SEABRA, A.P. Práticas de Química Orgânica. Editora EDART, 1987.

MARTINELLI, L. Produção de biodiesel etílico a partir da esterificação de ácidos graxos livres. Dissertação (Mestrado em Engenharia Química), Universidade Federal de Pernambuco, Recife-PE, 2008.

MARTINES, M.A.U., DAVOLOS, M.R., JÚNIOR, M.J. O efeito do ultra-som em reações químicas. Química Nova, v. 23, n. 2, p. 251-256, 2000.

MASON, T.J.; LORIMER, J.P. Applied sonochemistry: The uses of power ultrasound in chemistry and processing. Ed. Wiley-VCH, 2002.

MORETTO, E; FETT, R. Tecnologia de óleos e gorduras vegetais na indústria de alimentos. Varela Editora e Livraria Ltda., São Paulo, 1998.

RODRÍGUEZ, N. R.; BELTRÁN, S.; JAIME, I.; DIEGO, S. M.; SANZ, M. T.; CARBALLIDO, J. R. Production of omega-3 polyunsaturated fatty acid concentrates: A review. Innovative Food Science and Emerging Technologies, v. 11, p. 1-12, 2010.

SUSLICK, K. S. The chemical effects of ultrasound. Scientific American, v. 2, Nova Iorque, 1989

ULLMANN'S Encyclopedia, Industrial Organic Chemistry: Starting Materials and Intermediates, Wiley-VCH, Wheinheim, Germany, v. 4, p. 2481-2534, 1999.

VELOSO, Y. M. S.; FREITAS, L. F. L.; AMARAL FILHO, J. H. B.; SANTOS, I. T.; LEITE, M. S.; ARAUJO, P. J. L. Rotas para reutilização de óleos residuais de fritura. Cadernos de Graduação Ciências Exatas e Tecnológicas, v. 1, p. 11-18, 2012. 